\title{
Three billion years of fatty acid metabolism shape human cognitive performance
}

\author{
Paul M. Nealen* \\ Department of Biology, Indiana University of Pennsy/vania, Indiana, PA, USA \\ *Correspondence: pnealen@iup.edu
}

\section{A commentary on}

Sex differences in the relationship of dietary fatty acids to cognitive measures in American children

by William D. Lassek and Steven J. C. Gaulin (2011). Front. Evol. Neurosci. 3:5. doi: 10.3389/fnevo.2011.00005

Animal evolutionary history has progressed, in fits and starts, over several billions of years of changing environmental conditions on this planet. Ancient environments were strikingly different from modern conditions, and, in some cases, have left a permanent stamp on animal (including human) anatomy and physiology. Recently Lassek and Gaulin (2011) assessed the role which dietary fatty acids may play in shaping human cognitive performance, and in doing so, provide an intriguing glimpse into the evolution of animal nervous systems.

Using a large sample of American children aged 6-16 from the Third National Health and Nutrition Examination Survey [Center for Disease Control (CDC), 19881994], Lassek and Gaulin explored the statistical relationships between human cognitive performance (assessed via standardized math and reading tests) and dietary components, while controlling for other measures of subjects' social and environmental backgrounds (including lead exposure, family size and income, ethnicity). They found that dietary fatty acids, particularly $n-3$ ("omega-3") and $n-6$ forms, were positively and negatively related, respectively, to cognition scores in both male and female children. The benefits of dietary $n-3$ fatty acids were especially important for cognition in female children (Lassek and Gaulin, 2011).

Both $n-3$ and $n-6$ fatty acids are essential nutrients that must be obtained from dietary sources, and our Western diets are known to have relatively low $n-3: n-6$ ratios (Blasbalg et al., 2011). Why their opposite utility? And why of differential importance for males and females? Lassek and Gaulin (2011) suggest explanations which are rooted in our evolutionary past.

Our nervous systems contain a predominance of $n-3$ fatty acids, which Lassek and Gaulin (2011) hypothesize is due to the fact that animal neurons first evolved in an environment rich in $n-3$ fatty acids but limiting in $n-6$ fatty acids. Under these conditions, $n-3$ fatty acids became, and remain, critical for complete nervous development. Lassek and Gaulin cite corroborative evidence for the ability of $n-6$ fatty acids to compete with $n-3$ fatty acids for enzymatic access, suggesting that this competition is a direct mechanism for the differential utility of dietary $n-3$ and $n-6$ forms. Dietary intake of $n-3$ fatty acids is shown by Lassek and Gaulin to be especially important for females, which they suggest is due to the fact that female children must partition their dietary intake of these essential nutrients for both their own use as well as toward fat stores for later use as a nutritive source for the provisioning of developing offspring. Here, too, an ancient evolutionary shaping of our animal parental roles continues to represent itself in our utilization of dietary components, with implications for cognitive performance.

It is well understood that $n-3$ fatty acids are profoundly bio-active in neural as well as other tissues, with influence on cell membrane fluidity (Fernstrom, 1999; Schmitz and Ecker, 2008, and others), oxidative capacity (example in Maillet and Weber, 2007), and gene expression (recently reviewed in Bordoni et al., 2006). Their direct effects on the genesis, viability, and connectivity of neural tissues have also been demonstrated repeatedly in animal studies (as cited by Lassek and Gaulin, 2011), and their dietary importance to the neural development of human infants is also known (Hoffman et al., 2009; Leung et al., 2011; Muhlhausler et al., 2011; Salvig and Lamont, 2011).
Lassek and Gaulin (2011) now add to this body of knowledge by demonstrating the importance of dietary $n-3$ fatty acids beyond infancy into childhood and adolescence, and also provide evidence and explanation for the differential importance of dietary fatty acids for female children. In doing so, they highlight the need for more stringent consideration of $n-3$ dietary requirements during childhood as well as the need for more specific research on the mechanisms by which these essential nutrients influence human cognition. In using their evolutionary perspective, they also provide an important reminder of the need to consider evolutionary constraint in the shaping of our marvelously complex, yet very biologically, nervous systems - in many ways, we (still) are what we eat.

\section{ACKNOWLEDGMENT}

I thank Ethan Cullen for useful discussion and reference material.

\section{REFERENCES}

Blasbalg, T. L., Hibbeln, J. R., Ramsden, C. E., Majchrzak, S. F., and Rawlings, R. R. (2011). Changes in consumption of omega- 3 and omega- 6 fatty acids in the United States during the 20th century. Am. J. Clin. Nutr. 93, 950-962.

Bordoni, A., Di Nunzio, M., Danesi, F., and Biagi, P. L. (2006). Polyunsaturated fatty acids: from diet to binding to ppars and other nuclear receptors. Genes Nutr. $1,95-106$.

Center for Disease Control (CDC). (1988-1994). National Health, and Nutrition Examination Survey (NHANES. (III)). Hyattsville, MD: U.S. Department of Health and Human Services.

Fernstrom, J. D. (1999). Effects of dietary polyunsaturated fatty acids on neuronal function. Lipids 34, 161-169.

Hoffman, D. R., Boettcher, J. A., and Diersen-Schade, D. A. (2009). Toward optimizing vision and cognition in term infants by dietary docosahexaenoic and arachidonic acid supplementation: a review of randomized controlled trials. Prostaglandins Leukot. Essent. Fatty Acids 81, 151-158.

Lassek, W., and Gaulin, S. (2011). Sex differences in the relationship of dietary fatty acids to cognitive measures in American children. Front. Evol. Neurosci. 3:5. doi: 10.3389/fnevo.2011.00005 
Leung, B. M., Wiens, K. P., and Kaplan, B. J. (2011). Does prenatal micronutrient supplementation improve children's mental development? A systematic review. BMC Pregnancy Childbirth 11, 12. doi: 10.1186/1471-2393-11-12

Maillet, D., and Weber, J.M. (2007). Relationship between n-3 PUFA content and energy metabolism in the flight muscles of a migrating shorebird: evidence for natural doping. J. Exp. Biol. 210, 413-420.

Muhlhausler, B. S., Gibson, R. A., and Makrides, M. (2011). The effect of maternal omega-3 long-chain polyunsaturated fatty acid (n-3 LCPUFA) supplementation during pregnancy and/or lactation on body fat mass in the offspring: a systematic review of animal studies. Prostaglandins Leukot. Essent. Fatty Acids 85, 83-88.

Salvig, J.D., and Lamont, R.F. (2011). Evidence regarding an effect of marine n-3 fatty acids on preterm birth: a systematic review and meta-analysis. Acta Obstet. Gynecol. Scand. 90, 825-838.

Schmitz, G., and Ecker, J. (2008). The opposing effects of n-3 and n-6 fatty acids. Prog. Lipid Res. 47, 147-155.
Received: 21 November 2011; accepted: 22 November 2011, published online: 15 December 2011.

Citation: Nealen PM (2011) Three billion years offatty acid metabolism shape human cognitive performance. Front. Evol. Neurosci. 3:6. doi: 10.3389/fnevo.2011.00006

Copyright (c) 2011 Nealen. This is an open-access article distributed under the terms of the Creative Commons Attribution Non Commercial License, which permits non-commercial use, distribution, and reproduction in other forums, provided the original authors and source are credited. 